\title{
Lunar Station: The Next Logical Step In Space Development
}

\author{
By \\ Mr. Robert Bruce Pittman* \\ Ms. Lynn Harper** \\ Mr. Mark Newfield** \\ and Dr. Daniel J. Rasky** \\ * - Space Portal, Lockheed; ** - Space Portal, NASA Ames
}

September, 2014

The International Space Station (ISS) is the product of the efforts of sixteen nations over the course of several decades. It is now complete, operational, and has been continuously occupied since November of $2000^{1}$. Since then the ISS has been carrying out a wide variety of research and technology development experiments, and starting to produce some pleasantly startling results. The ISS has a mass of 420 metric tons, supports a crew of six with a yearly resupply requirement of around 30 metric tons, within a pressurized volume of 916 cubic meters, and a habitable volume of 388 cubic meters. Its solar arrays produce up to 84 kilowatts of power. In the course of developing the ISS, many lessons were learned and much valuable expertise was gained. Where do we go from here?

The ISS offers an existence proof of the feasibility of sustained human occupation and operations in space over decades. It also demonstrates the ability of many countries to work collaboratively on a very complex and expensive project in space over an extended period of time to achieve a common goal. By harvesting best practices and lessons learned, the ISS can also serve as a useful model for exploring architectures for beyond lowearth-orbit (LEO) space development.

This paper will explore the concept and feasibility for a Lunar Station. The Station concept can be implemented by either

http://www.nasa.gov/mission_pages/station/main/\#.VA 58bI1dVS8 putting the equivalent capability of the ISS down on the surface of the Moon, or by developing the required capabilities through a combination of delivered materials and equipment and in situ resource utilization (ISRU). Scenarios that leverage existing technologies and capabilities as well as capabilities that are under development and are expected to be available within the next 3-5 years, will be examined. This paper will explore how best practices and expertise gained from developing and operating the ISS and other relevant programs can be applied to effectively developing Lunar Station.

Why Lunar Station? - A Lunar Station can provide many benefits to NASA and the country. It would serve as a necessary step between our current capabilities in LEO, and our aspirations to one-day travel in person to Mars. It can provide a testing and proving ground for a variety of important advanced technologies and capabilities, including robotics, ISRU, resource depots, deep space crew habitats, closed loop life support, in-space propulsion, optical communication and space additive manufacturing to name a few. Its unique lunar environment, including large permanently shaded craters with temperatures as low as $40^{\circ} \mathrm{K}\left(-388^{\circ} \mathrm{F}\right)^{2}$, offers opportunities for new scientific observations, exploration, investigation, and learning. Lunar Station will give our space program a much-needed logical next step to strengthen our relevance

\footnotetext{
2 http://www.space.com/7311-moon-craters-coldestplace-solar-system.html
} 
with the public, maintain our international space leadership, and hone our technical cutting edge.

\section{Lunar Exploration - A Brief History}

President Kennedy launched the Apollo Program in May 1961. This program sent 12 Americans to the surface of the Moon between July 1969 and December $1972^{3}$. The Apollo-17 astronauts were the last humans to visit the Moon. A recent assessment put the program cost for Apollo at $\$ 174$ billion in today's dollars 4 . Planned missions beyond Apollo-17 were cancelled, even though the Saturn-5 rockets had been built and were operational, because of the large cost of the program. Despite the unquestionable success of Apollo, many people now realize that the suite of conditions that enabled it was an anomaly that is not likely to be repeated. No one has been back to the Moon, or even travelled beyond LEO, in 42 years.

After the Apollo program, the Moon was mostly ignored for many years. The first US mission to the Moon after Apollo was the Clementine mission in 19945. This was a low cost mission that mapped the lunar surface and returned tantalizing hints of the presence of water in the permanently shadowed lunar craters.

In Oct. 2009, the LCROSS mission impacted one of these permanently shadowed craters and the data obtained from this project confirmed the presence of large quantities of water, as well as methane, ammonia, carbon dioxide and carbon

\footnotetext{
3 http://www.nasa.gov/mission_pages/apollo/

${ }^{4}$ http://beforeitsnews.com/space/2014/03/nasaend-manned-space-flight-2-2476914.html 5

http://www.nasa.gov/mission_pages/LCROSS/sea rchforwater/clementine.html
}

monoxide6; all very useful materials for future lunar activities.

\section{Returning To The Moon: If At First You Don't Succeed ...}

On July $20^{\text {th }} 1989$, the $20^{\text {th }}$ anniversary of the Apollo 11 landing, President George H.W. Bush initiated the Space Exploration Initiative to return Americans to the Moon and eventually to Mars7. A NASA "90 Day Study" group was formed to explore options to carry out this assignment. The price tag for this 20-30 year program came out to be a whopping $\$ 400-500$ billion. The program quietly died in the early 1990's.

On February $1^{\text {st }} 2003$ the Space Shuttle Columbia disintegrated upon reentry over Texas killing all seven astronauts on board. Responding to this disaster President George W. Bush rolled out an extraordinary Vision for Space Exploration (VSE) $^{8}$ on January 14,2004 . The VSE had been carefully developed and had four major thrusts:

1. Implement a sustained and affordable human and robotic program to explore the solar system and beyond.

2. Extend human presence across the solar system, starting with a human return to the Moon by the year 2020, in preparation of human exploration of Mars and other destinations.

3. Develop the innovative technology, knowledge and infrastructures both to explore and to support decisions about the destinations for human exploration.

4. Promote international and commercial participation in exploration to further U.S. scientific, security and economic interests.

\footnotetext{
http://www.nasa.gov/mission_pages/LCROSS/mai $\mathrm{n} /$ index.html

$7 \mathrm{http}: / /$ history.nasa.gov/sei.htm

8 http://history.nasa.gov/sep.htm
} 
There were several important new elements in the VSE as well:

1. Direct references to sustainable, affordable and flexible exploration.

2. The realization that infrastructure would be needed to enable this longterm exploration.

3. The focus on using lunar and asteroid materials to reduce the mass that must be transported from Earth.

4. The instruction to "Pursue commercial opportunities for providing transportation and other services support for the International Space Station and exploration missions beyond low Earth orbit".

5. Return US astronauts to surface of the Moon by 2020.

To fulfill the VSE, new NASA Administrator Mike Griffin initiated the Constellation Program ${ }^{9}$. Constellation consisted of two launch vehicles: the Ares-1 for launching crew, and the Ares-5, a large heavy lift launch vehicle for cargo. In addition to the launch vehicles, there was also a new crew capsule (Orion) and a large lunar lander (Altair) proposed. Following the program rollout in the autumn of 2005 , a number of criticisms quickly arose regarding the viability of the proposed launch systems, particularly the Ares-1. Work proceeded on Constellation despite these criticisms.

In May 2009 newly elected President Barack Obama commissioned a "Review of the US Human Spaceflight Plan Committee" (the Augustine Committee ${ }^{10}$ ). The Committee spent five months reviewing the Constellation program and concluded that, contrary to the VSE guidelines, the program was not "sustainable". On February 1 st, 2010 with the rollout of the his FY 2011 NASA budget, President Obama

9

http://www.nasa.gov/mission_pages/constellation /main/index2.html

10 http://www.nasa.gov/offices/hsf/home/ cancelled the Constellation program and retargeted NASA to send astronauts to an asteroid, rather than returning them to the Moon.

The cancellation of the Constellation program and the re-vectoring of US human space program to visiting an asteroid, rather than returning to the Moon, was a major blow to many in the aerospace community. It was a blow to a number of members of Congress as well. Congress reacted by demanding a standup of a new heavy lift rocket program, the Space Launch System or SLS (essentially the Ares-5 launch vehicle), to take the place of Constellation. SLS along with the Orion crew capsule remain the NASA principle programs of record for human exploration beyond LEO as of the time of this writing. The current public program objective of SLS/Orion is to provide transport for astronauts to an unspecified asteroid in the mid to late 2020's that will be moved to a cis-lunar location, and eventually on to Mars in the 2030's.

\section{Engaging Emerging Commercial Space}

At the time that the Constellation program was being pursued, NASA made a very wise decision to engage the emerging commercial space industry. The Commercial Orbital Transportation Services (COTS) program was instrumental in developing new US launch capabilities at very low cost and risk to the government. COTS is used in this paper as a model for future space capability development.

In January 2006, NASA announced the COTS program. The objective of the program was to demonstrate the capability of commercial providers to deliver cargo and potentially crew to the International Space Station (ISS) at a lower cost than traditional aerospace operating under standard contracting approaches. An initial program budget of $\$ 500 \mathrm{M}$ was made available and awards were made through 
competitively selected NASA funded Space Act Agreements (SAA). The use of the SAA is important because it offered an alternative to the cost plus contracts that were typically used by NASA for large space development projects. The SAA's utilized performance-based milestones: Companies would only be paid a previously agreed amount upon successful completion of milestone. This model turned out to be very effective and is now referred to in this document as the "Commercial Leverage Model."11

Twenty-one proposals were received in response to the COTS program solicitation, and initial award selection went to two companies: SpaceX ${ }^{12}$ run by Elon Musk and RocketPlane Kistler ${ }^{13}$ run by George French. The program was executed using pre-negotiated, firm fixed price milestones and associated payments. SpaceX met all of their milestones leading to the development and successful launch of a Falcon-9 rocket in June 2010, and a demonstration flight of their Dragon spacecraft to the ISS in May 2012 - an historical first for a private company.

Rocketplane Kister did not fare as well. After completing some early milestones, they were unable to meet a key-financing milestone. Their agreement with NASA was eventually canceled in October 2007. The funds made available by this cancelation were then re-competed and this time Orbital Sciences ${ }^{14}$ (Orbital) received an award. Similar to SpaceX, Orbital proceeded to meet all their milestones and in April 2013 successfully demonstrated their new Antares launch vehicle. Then in September of 2013, Orbital became the second private company to successfully launch and berth their resupply module, Cyngus, to the ISS.

\footnotetext{
${ }^{11}$ Pittman, Rasky, Harper, IAC-12, D3,2,4,x14203

12 http://www.spacex.com/

${ }^{13} \mathrm{http}: / /$ www.kistler.co/

14 https://www.orbital.com/
}

A formal assessment of the COTS program by NASA ${ }^{15}$ showed unambiguously that the commercial leverage model could reduce development costs by an order of magnitude over traditional development methods.

While both SpaceX and Orbital were working to complete their COTS program milestones, NASA awarded them two large, competitively selected service contracts under the Commercial Resupply Services (CRS) program ${ }^{16}$. The award was for eight ISS cargo flights valued at about $\$ 1.9$ billion from Orbital Sciences, and 12 cargo flights valued at about $\$ 1.6$ billion from SpaceX. Added to the financial incentive from the COTS program, these additional contract awards were very welcome news to the companies as they worked to develop and demonstrate their cargo launch capabilities for the ISS.

Since 2009, following the very successful COTS and CRS example, NASA has been pursuing a similar approach to establish commercial based crew transportation to the ISS. The Commercial Crew Program (CCP), used the same commercial leverage model that was used for COTS. The CCP was divided into four phases. On September 16, 2014 the final Commercial Crew Transportation Capability (CCtCap) phase was announced with awards going to Boeing and SpaceX. This phase will fund the two companies, $\$ 4.2$ billion for Boeing and $\$ 2.6$ billion to SpaceX, to demonstrate crew to ISS transfer of up to seven astronauts by late 2017 . The capsules will also serve a lifeboat function at the ISS and will allow the crew size to increase from six to at least seven.

At the time that NASA was pursuing the COTS program, the privately funded Google Lunar XPRIZE was announced 17 in September 2007. With a prize purse of

\footnotetext{
15 http://www.nasa.gov/pdf/586023main_8-3-11_NAFCOM.pdf 16 http://www.nasaspaceflight.com/2008/12/spacexand-orbital-win-huge-crs-contract-from-nasa/ 17 http://www.googlelunarxprize.org/
} 
\$30 million, it was an audacious challenge: Send a robotic spacecraft to the Moon, land safely, traverse across the surface at least 500 meters and send back video and other information from the Moon to the Earth. The first private team to accomplish this by December 31, 2015 will be awarded $\$ 20$ million, with a second place prize of $\$ 5$ million, and $\$ 5$ million in bonus prizes. Currently, with a little over one year left to accomplish the task, there are still 18 official teams in the competition and at least 5 of the teams have made significant progress toward the goal. From the beginning of the competition it was clear that it was going to cost significantly more than $\$ 20$ million to win the prize, and so fund raising would be one of the major challenges for the competing teams.

The winning of the XPRIZE will be an enormous feat: these will be the first privately funded craft to land on the Moon ... but what then? If the Google Lunar XPRIZE's stated goal of "inspiring a new generation of private investment in space technology" is to be fully realized, the achievements of these private lunar pioneers will only have been a first step. The question that must then be addressed is what comes next?

It is clear that the teams involved in the Google Lunar XPRISE are looking beyond the scope of the competition. These organizations will be in a unique position to scale up their work and land increasingly large payloads onto the lunar surface with growing efficiency and even return samples to Earth. But without some kind of organizing element, this could lead to wasteful duplication or even destructive competition.

The Google Lunar XPRIZE teams who were hoping to provide transport and other services to support NASA's Constellation lunar program were negatively affected by its cancelation in early 2010 . To help at least partially compensate for this change, in October 2010, NASA announced the selection of six companies to participate in the Innovative Lunar Demonstration Data (ILDD) program 18 . ILDD was a $\$ 30$ million program targeted at the US XPRIZE teams to offer up to $\$ 10$ million to each team in exchange for sharing data about their development process and experience with NASA.

In 2009 the NASA Ames Research Center Space Portal Office and the State of Hawaii Department of Aerospace Development in collaboration with colleagues from around the world rolled out the concept for an International Lunar Research Park (ILRP)19,20. The concept was to develop a self-supporting research park on the Moon in three phases:

1. Establish high fidelity lunar analog sites on Earth to develop, explore and verify needed technologies and capabilities.

2. Establish a "lunar robotic village" on the Moon with advanced and collaborative robotics, additive manufacturing and in-situ resource utilization to prepare the site for eventual human occupation.

3. Send humans to the Moon to begin living and working there while continuing to advance capabilities of the ILRP, and developing useful and revenue making products.

This concept was found to be compelling to a number of high-profile individuals, was discussed at length during several international meetings, and described in several conference papers. It was even

18 http://www.nasa.gov/home/hqnews/2010/oct/HQ_10259_ILDD_Award.html

${ }^{19}$ International Lunar Research Park

https://sites.google.com/site/internationallunarresearch park/

${ }^{20}$ International Lunar Research Park Exploratory Workshop

https://sites.google.com/site/ilrpexploratoryworkshop2 011/ 
featured on This Week at NASA ${ }^{21}$. Unfortunately, similar to many of the Google Lunar XPRIZE competitors, it was found that without a significant commitment by the government to pursue human lunar space activities, the technical and financial risks are too large to attract sufficient investment to get the ILRP off the ground.

\section{Recent Developments}

A number of relevant and notable developments that could significantly affect the nation's space activities and programs have begun to emerge. Leveraging these activities could significantly reduce the cost and speed the development of the Lunar Station concept.

First, SpaceX ${ }^{22}$ recently launched their thirteenth successful Falcon-9 rocket (in thirteen attempts) and are working on three important new capabilities:

1. Development of a reusable Falcon-9 launch system (Falcon-9R) which could significantly reduce launch costs even further from their $\sim \$ 60 \mathrm{M}$ currently for a Falcon-9 that launches 13.5MT to low-earth-orbit (LEO), down to around $\$ 10 \mathrm{M}$ per launch. This is easily a factor of ten below current space industry pricing.

2. Development of a Falcon-heavy (Falcon-H) that will be capable of putting over 50MT to LEO for a price of $\sim \$ 135 \mathrm{M}$, and which is expected to fly in 2015. The closest current available US capability is $\sim 23 \mathrm{MT}$ that can be lofted to LEO by a Delta-4 Heavy rocket for a price of $\sim \$ 380 \mathrm{M}$.

3. Development of a new liquidoxygen/methane rocket engine (called Raptor) with approximately a one-million pound thrust capability -similar to the engines used on the NASA Saturn-5 first stage. The inten-

21

http://www.nasa.gov/multimedia/podcasting/TWAN_04 _15_11.html

22 http://www.spacex.com/ tion apparently is to use this engine to power a Falcon-super-heavy rocket that could loft $\sim 200 \mathrm{MT}$ to LEO to support crewed Mars missions. SpaceX CEO Elon Musk calls this new vehicle the Mars Colonial Transport (MCT).

Second, Bigelow Aerospace continues to advance their expandable space modules, following the successful in-space demonstrations of two scale models in 2006 and 2007 that are still in orbit. Bigelow Aerospace now has a contract with NASA to put a small module called the Bigelow Expandable Activity Module or BEAM ${ }^{23}$ on the ISS starting in 2015. In addition, Bigelow is currently advertising a bigger expandable module they call the BA-330 that has a pressurized volume of $330 \mathrm{cu}-$ bic meters, and which they say could serve as a deep-space habitat for four to six crew for an extended period.

The investment community is now showing interest in lunar exploration and development. On Saturday, August 23, 2014 a workshop was held at the noted Silicon Valley venture capital investment house, Draper-Fischer-Jurvetson (DFJ). The title of the workshop was "Low Cost Strategies for Lunar Settlement", and it was organized by Steve Jurvetson of DFJ. The workshop brought together about 50 scientists, engineers, executives and entrepreneurs, who have significant backgrounds and interests in lunar exploration and development, including a number of NASA and former NASA personnel and an Apollo astronaut. The group was assembled to answer the question: Is it possible to have a permanent human lunar settlement of about 10 people on the Moon by 2022, for a price tag of $\$ 5$ billion or less? The surprising consensus answer to this question was a qualified "Yes, under the right organizational and funding conditions". There were no technical show-

http://www.nasa.gov/mission_pages/station/news/bea m_feature.html 
stoppers and a great deal of the technologies needed were either on the shelf or could be developed in a relatively short period of time using contemporary techniques. The group agreed to write a set of papers outlining those conditions, and NewSpace magazine will dedicate a future issue to publishing the results.

One particularly interesting idea that emerged from the meeting was the "Apollo Prize ${ }^{24 "}$. This would be a $\$ 1$ billion dollar prize for the first organization that succeeded to "Transport two or more people to the surface of the Moon, and then return them safely back to Earth". Several individuals are now pursuing this idea in earnest.

Outside of the US, interest continues to grow for pursuing human missions to the Moon. Most recently the Chinese have clearly shown their intents concerning the Moon with their successful Chang'e-3 lunar robotic spacecraft ${ }^{25}$. The Russians have also recently stated their interest in putting Russian cosmonauts on the Moon ${ }^{26}$. The International Space Exploration Coordination Group (ISECG) is comprised of members representing the space agencies of 14 countries. The ISECG has produced a Global Exploration Roadmap ${ }^{27}$ and the near term goal of the vast majority of this groups members is the Moon.

\section{Returning To The Moon: Lunar Station - The Next Logical Step}

The intent of the Lunar Station is to put a permanent human facility on the Moon using the demonstrated capabilities and best practices derived from the development and operation of the International Space Station. Lunar Station would be a

\footnotetext{
${ }^{24}$ Courtesy Charles Miller, spacepolicy@yahoo.com

25 http://www.universetoday.com/107716/china-

considers-manned-moon-landing-following-

breakthrough-change-3-mission-success/

${ }^{26} \mathrm{http}: / /$ rt.com/news/157800-russia-moon-

colonization-plan/

${ }^{27}$ http://www.nasa.gov/exploration/about/isecg/\#.VAgRI1dVS
}

facility capable of supporting crews of 610 people by providing shelter, power, life support, communications and the ability to egress from the facility and travel across the surface of the Moon. It is envisioned to be developed primarily through a consortium of public, private, and international contributors, and would be the kernel around which the broader capabilities of the ILRP could nucleate. The Lunar Station community would jointly develop and share infrastructure as well as separately develop and own specific capabilities. Activities would range from scientific research and technology development, to resource mining and processing, to human exploration of the Moon and even tourism.

The existence proof that this type of enterprise can be developed successfully beyond Earth is the ISS, which was built and continues to be used by sixteen countries. The ISS now features commercial as well as science and technology activities, and has been continuously inhabited since November 2000. Similar to the ISS but with a broader set of stakeholders in mind, Lunar Station will be developed with investments from nations, commercial developers, philanthropists, academic institutions and even private citizens to develop and evolve the facilities over time.

For the purposes of the analysis we will use the ISS as a guide for establishing the initial capabilities that will be targeted for Lunar Station. These are listed as follows.

\section{Lunar Station Initial Goals:}

$\begin{array}{ll}\text { Pressurized volume: } & 900+\text { cubic meters } \\ \text { Habitable volume: } & 300+\text { cubic meters } \\ \text { Power: } & 100+\text { KW } \\ \text { Initial crew size: } & 6-10 \text { people } \\ \text { Life support recovery: } & 90 \% \text { or better } \\ \text { Crew rotation: } & \text { Every six months } \\ \text { Initial lunar mass: } & 150+\text { MT } \\ \text { Initial yearly resupply: } & 30+\text { MT }\end{array}$

The largest delta with respect to ISS numbers is the initial lunar mass of $150+\mathrm{MT}$ compared to the ISS mass of 
420 MT. We believe this lower mass is enabled by using the soon to be available pre-fabricated Bigelow Aerospace habitat modules (described in more detail below) compared to the traditional hard-body modules used on ISS. Mass savings can also be anticipated from the effective use of ISRU and additive manufacturing (discussed more below). With the current and near term capabilities of emerging commercial space companies, such as SpaceX and Bigelow Aerospace, building a lunar facility that meets these goals appears very feasible at this time, as will be discussed.

In considering a budget for both the build and operational phases of Lunar Station ISS again served as a guide. It is assumed that the initial effort will result from a largely government-funded program. The current annual budget for the ISS runs about $\$ 3$ billion per year. Given contemporary commercial capabilities and approaches, and to promote more costeffective choices, an annual budget level of approximately $\$ 2$ billion per year for Lunar Station is considered. Of the $\$ 2$ billion, roughly half is assigned to transportation with the remainder funding payloads and operations. Once the initial station is underway, additional funding from international and private partners is anticipated.

An essential capability for building and operating Lunar Station is transportation to the Lunar surface. Table 1 gives a summary of current US transportation options beyond LEO, including listing the capabilities of the NASA Saturn-5 rocket for comparison (cost numbers for the Saturn- 5 have been adjusted to current year values). The data in the table come from a variety of public sources and incorporate a number of assumptions as well as engineering and professional judgment. As such, these numbers should be used more for comparison of different launch options than numbers for detailed mission planning.

As can be seen from the table, the recent and future development of the SpaceX launch capabilities could be very important to achieving an economically viable approach for build and operating Lunar Station. Assuming a transportation budget of approximately $\$ 1$ billion per year as previously discussed, the time frames to achieve $150 \mathrm{MT}$ on the lunar surface run from a little over nine years using a Falcon-9, down to five years for a Falcon-H, and down to three years using a Falcon-HLRF (described below). Also, the Falcon-H and Falcon-HLRF are the only options that achieve the operational requirement of $30+$ MT yearly re-supply for approximately $\$ 1$ billion a year of transportation costs. Note the other launch options require a considerably longer time to get the $150 \mathrm{MT}$ of payload to the lunar surface, with a minimum of 26 years using a Delta- 4 heavy. Also all the other options fall considerable short of the 30+MT yearly re-supply requirement for $\$ 1$ billion of transportation costs.

Falcon-HLRF stands for Falcon-heavy, LEO Re-Fueled. It is an extrapolation by the authors on the kind of launch capability that could be achieved by combining a Falcon-H with multiple flights of a future low-cost reusable Falcon-9R. The idea is to put a Falcon-H "tanker" (Falcon-HT) into LEO, partially fueled, and then top-off through the rendezvous and fuel transfer of multiple (approximately 10) Falcon-9R flights carrying only fuel for payload. This would provide a low-failure consequence, high-flight rate payload for the Falcon-9R that is well tuned to its reusable capabilities. With the fully fueled Falcon-HT in LEO, a second Falcon-H with its lunar payload is launched to LEO, retaining its second stage after main-engine cut-off. This Falcon- $\mathrm{H}$ then rendezvous with the Falcon-HT, transfers fuel to refill the retained Falcon-H second stage (similar to 
aircraft aerial refueling), separates from the Falcon-HT, and then re-fires its retained second stage to perform the translunar-injection burn. Note comparing the Falcon-HLRF to the numbers for the Saturn-5 vehicle, that this approach would yield Saturn-5 type lunar payload capabilities for a fraction of the historical costs of the Saturn-5. Also this large payload capability may be particularly useful for sending prefabricated crew habitats to the lunar surface as discussed below.

Concerning the SLS rocket currently under development by NASA, note that its capabilities are similar to the Saturn-5, particularly the SLS-Block2, while being somewhat lower cost. However, because of its low expected flight rate and significant costs, it doesn't appear to fit within the cost envelope for supporting Lunar Station.

As mentioned earlier, a very good option for a crew habitat is soon to be available from Bigelow Aerospace (BA). Real estate entrepreneur Bob Bigelow founded BA in 1999. BA licensed technology from the NASA Transhab project that was developing expandable space habitats for sending astronauts to Mars. Although NASA was making excellent progress and developing very promising technology, Congress canceled the Transhab program in 2000. Starting with the NASA technology base, Bigelow invested over a decade of effort and $\sim \$ 250$ million of his own money to develop and flight-test this technology for in-space crew habitats. In 2006 and again in 2007 BA launched two small technology demonstration modules: Genesis 1 and 2. These units have performed very well and are still operational. Bigelow is now well into the development of the BA-330 which as the name implies will have 330 cubic meters of pressurized volume and mass of $\sim 20 \mathrm{MT}$. Each of these modules is capable of supporting up to six crewmembers for an extended period of time. While the original BA-330 is designed for
LEO, BA is currently developing an enhanced version, the BA-330MDS for lunar surface operation.

Once initial goals have been specified and viable transportation and crew habitat options have been identified, the next decision is the location for Lunar Station; i.e., site selection. A number of different locations could be proposed, but the polarregions provide three key benefits:

1. Continuous sun-light providing continuous power

2. Access to cold-traps in permanently shadowed craters that hold stores of water and useful hydrocarbons

3. Lower surface temperature swings compared to off-polar locations.

Once a facility is established at a pole, eventual exploration and development missions to off-polar locations could then be pursued. Site locations at both the South and North Lunar poles should be considered, but based on the more advantageous topography, we initially are selecting Peary crater ${ }^{28}$ at the Lunar North pole for our assessment. Further analysis and discussion would be needed to finalize the selection, but other lunar experts have noted the attributes of this site ${ }^{29}$. We suggest therefore that Peary crater be treated as the "site to beat" relative to other site candidates.

\section{Lunar Station Build Scenario}

Precursor Missions - We propose a Lunar Station build scenario as follows. First a series of precursor robotic missions would be sent to Peary crater to do a "resources and hazards" assessment. This would provide both surface truth data about the resources in the permanently shadowed crater as well as the ter-

28

http://www.nasa.gov/mission_pages/LRO/multimedia/l roimages/lroc-20091224-peary-crater.html

${ }^{29}$ http://www.space.com/957-perfect-spot-moonbase.html 
rain on the northern rim of the crater that is exposed to almost constant sunlight according to the orbital images from several lunar orbiter missions the, most recent being the NASA Lunar Reconnaissance Orbiter ${ }^{30}$ (LRO). The precursors will be searching for volatiles in the crater and a suitable landing site and base location on the crater rim.

Power and Comm - Assuming this site is evaluated to be a suitable location, a series of missions to prepare the site would then be launched. One of the first elements to be landed would be a $100 \mathrm{KW}$ solar Power and Communication station (weighing approximately $4 \mathrm{MT}$ ) with a $100 \mathrm{~m}$ tall boom to continuously collect sunlight and convert it into electricity. A graphic illustration of such a power station, courtesy of SkyCorp ${ }^{31}$ is shown in Figure 1.

Site Prep - Managing dust at the landing sites and habitats is a significant issue. Inspired by the utility of rugged flexible Bobcats $^{\mathrm{TM}}$, electrically powered multifunction excavators, or "MoonCats" would then be brought to the site to level off the terrain for both the landing pads and the habitation site. Equipment to either sinter or otherwise stabilize the regolith would then be sent to the site. All of the equipment would be operated autonomously or through tele-operations from Earth. Once the landing pads and berms were put in place, roadways would be constructed from the regolith leading from the landing pads to the habitation site. The habitation site would be sized to initially accommodate up to three BA330MDS for crew habitat and operations.

ISRU and Additive Manufacturing - Insitu resource utilization along with additive manufacturing may provide significant benefits for building and operating

\footnotetext{
${ }^{30}$ http://lunar.gsfc.nasa.gov/

${ }^{31}$ http://www.skycorpinc.com/Skycorp/Home.html
}

Lunar Station. However, much more will need to be learned about resources at the site, effective procedures and processes, required precursor materials and equipment, hazards and potential malfunctions, and methods of repairs before firm plans can be made relying on these capabilities and approaches. Pursuing experiments and investigations on a small scale during the site preparation period would be very advantageous in-order to make the required assessments and establish effective procedures. This in turn could lead to the integration of an appropriate level of ISRU and additive manufacturing into the station build and operation plans.

Landing Crew Habitats - Once the site prep has been completed, BA-330's would then be sent to the lunar surface. Given their large gross mass of 20MT, the easiest way to accomplish this maybe to use a Falcon-HLRF to deliver a BA-300 to LowLunar-Orbit (LLO). There it could rendezvous with four "Lunar Descent Mules" that have been pre-positioned in LLO by earlier Falcon-H or Falcon-HLRF launches. The four lunar descent mules would then lower the BA-330MDS to the Lunar Station site landing pad area. This is illustrated conceptually in Figure 2. The BA330 would then be picked up by previously sent "Lunar Surface Mules" and moved to the habitation site where it would be positioned and potentially joined together with other modules, as illustrated in Figure 3. Power from the power station would then be connected to the habitats for operation.

Crew Transport - With the habitats in place, crew could then be sent to Lunar Station to begin its permanent occupancy. One way this could be accomplished is to pre-position a "Gryphon" reusable crew lunar lander at LLO using a Falcon-H. Then a crew of four to six could be sent on a "Deep Space Dragon" (DSD) to LLO using a second Falcon-H. The DSD would rendezvous with the Gryphon lander, the 
crew and light payloads would transfer to the Gryphon, the Gryphon would detach from the DSD, and then descend to the lunar surface. For departure from the Moon, the crew would re-board the Gryphon lander and ascend to LLO for rendezvous with the orbiting DSD , separate from the Gryphon, and then fire the Dragon engines for return to Earth using direct entry.

Initial Operating Capability and Resupply - With the initial infrastructure and crew in-place, Lunar Station would begin its initial operations. Focus would be on investigations for resources and hazards, possibilities for food growth and bioregenerative life support, ISRU activities and assessments, and medical and life sciences investigations affecting long term habitation in low gravity. After a sufficiently robust initial operating capability is achieved, attention could turn to expanding and evolving Lunar Station into a more multi-function, multi-asset facility accommodating a greater number of people and capabilities, and bringing on additional private, government and international partners that leverage and expand the infrastructure. The aim would be to eventually grow to a fully functional International Lunar Research Park, pursuing both private and government interests and activities. This would include lunar capabilities and resources that would be very beneficial for NASA to use to accomplish our aspirations for human explorations of Mars.

\section{A Business Case For The Moon}

Experience with the Google Lunar XPRIZE and the ILRP shows that the prospects are dim for private interests alone to accomplish significant lunar surface activities at this time - it's just too expensive and too risky. In order for lunar development to become a reality, there is a clear need for the government to make key investments to lower technical and financial risks Lunar Station would be a wise approach in this regard. There are many historic precedents for this type of government investment including the interstate highway system, municipal utilities, and the internet. Recent NASA programs such as COTS/CRS have also demonstrated the efficacy and benefits of this approach. The public/private and international partnerships that would likely develop following the initial government investment in Lunar Station would further extend its capabilities and functions, while providing beneficial lunar activities, resources and possible revenue streams. This is how a solid business case for the Moon can be accomplished.

\section{Conclusions}

With the ISS built and operational, our space program needs a clear, timely, achievable, and highly engaging next step. This next step must also serve as an enabling pathway for NASA's ultimate goal of human missions to Mars and human or robotic exploration and development of asteroids and other planetary bodies. A clear, achievable and highly engaging next step is also essential for NASA to maintain its relevance to the US public, its leadership in the international community, and its technical cutting edge. Lunar Station could meet these objectives, as our initial analysis has shown.

Lunar Station falls inside of reasonable time-lines (about 5 years to build) and budget levels $(\sim \$ 2$ billion/year to build and operate) and can be accomplished with current and near term capabilities. Pursued under the feasibility proof of ISS, using best practices extracted from its build and operation, and combined with the current and emerging capabilities from the traditional and emerging aerospace industry, Lunar Station is the logical next step in space development. 
Table 1 - Comparison of launch options for building and operating Lunar Station

\begin{tabular}{|c|c|c|c|c|c|c|c|c|c|}
\hline Lunar Station Launch Options* & Saturn-5 & SLS-Block1 & SLS-Block2 & Atlas-5 401 & Delta-4 Heavy & Falcon-9 & Falcon-H & Falcon-HLRF & Falcon-9R \\
\hline Launch vehicle fixed price $(M \$ / y r)$ & $\$ 3,169$ & $\$ 1,500$ & $\$ 1,500$ & $\$ 0$ & $\$ 0$ & $\$ 0$ & $\$ 0$ & $\$ 0$ & $\$ 0$ \\
\hline Launch vehicle variable price (M\$/unit) & $\$ 565$ & $\$ 500$ & $\$ 750$ & $\$ 187$ & $\$ 380$ & $\$ 62$ & $\$ 135$ & $\$ 250$ & $\$ 10$ \\
\hline LEO Payload Cap (MT) & 117.5 & 70.0 & 130.0 & 9.8 & 23.0 & 13.2 & 53.2 & 140.7 & 9.2 \\
\hline TLI Payload Cap (MT) & 45.6 & 30.0 & 56.4 & 4.2 & 9.8 & 4.6 & 18.6 & 47.2 & N/A \\
\hline \# Launches/yr & 1 & 0.5 & 0.33 & 4.2 & 2 & 11 & 5 & 3 & 28.5 \\
\hline Total Price $(M \$)$ per LEO Launch & $\$ 3,734$ & $\$ 3,500$ & $\$ 5,295$ & $\$ 187$ & $\$ 380$ & $\$ 62$ & $\$ 135$ & $\$ 250$ & $\$ 10$ \\
\hline Cruise stage and lander price ( $M \$$ /unit) & $\$ 375$ & $\$ 250$ & $\$ 375$ & $\$ 50$ & $\$ 100$ & $\$ 25$ & $\$ 54$ & $\$ 82$ & $N / A$ \\
\hline Total Price (M\$) per Lunar Launch & $\$ 4,109$ & $\$ 3,750$ & $\$ 5,670$ & $\$ 237$ & $\$ 480$ & $\$ 87$ & $\$ 189$ & $\$ 332$ & $\$ 10$ \\
\hline Lunar Surface Payload Cap (MT) & 16.4 & 8.8 & 16.3 & 1.2 & 2.9 & 1.5 & 6.0 & 16.9 & $N / A$ \\
\hline MT/yr to Lunar Surface & 16.4 & 4.4 & 5.4 & 5.1 & 5.8 & 16.4 & 30.1 & 50.7 & N/A \\
\hline Launch Cost/yr (M\$) & $\$ 4,109$ & $\$ 1,875$ & $\$ 1,871$ & $\$ 995$ & $\$ 960$ & $\$ 957$ & $\$ 947$ & $\$ 996$ & $\$ 285$ \\
\hline $\begin{array}{l}\text { \# Launches to get 150MT on the Lunar } \\
\text { Surface }\end{array}$ & 9.2 & 17.1 & 9.2 & 122.4 & 52.2 & 100.6 & 24.9 & 8.9 & N/A \\
\hline $\begin{array}{l}\text { Years to get 150MT on the Lunar } \\
\text { Surface }\end{array}$ & 9.2 & 34.3 & 28.0 & 29.2 & 26.1 & 9.1 & 5.0 & 3.0 & $N / A$ \\
\hline
\end{tabular}

Notes: * - Cost and other data from a variety of public sources.

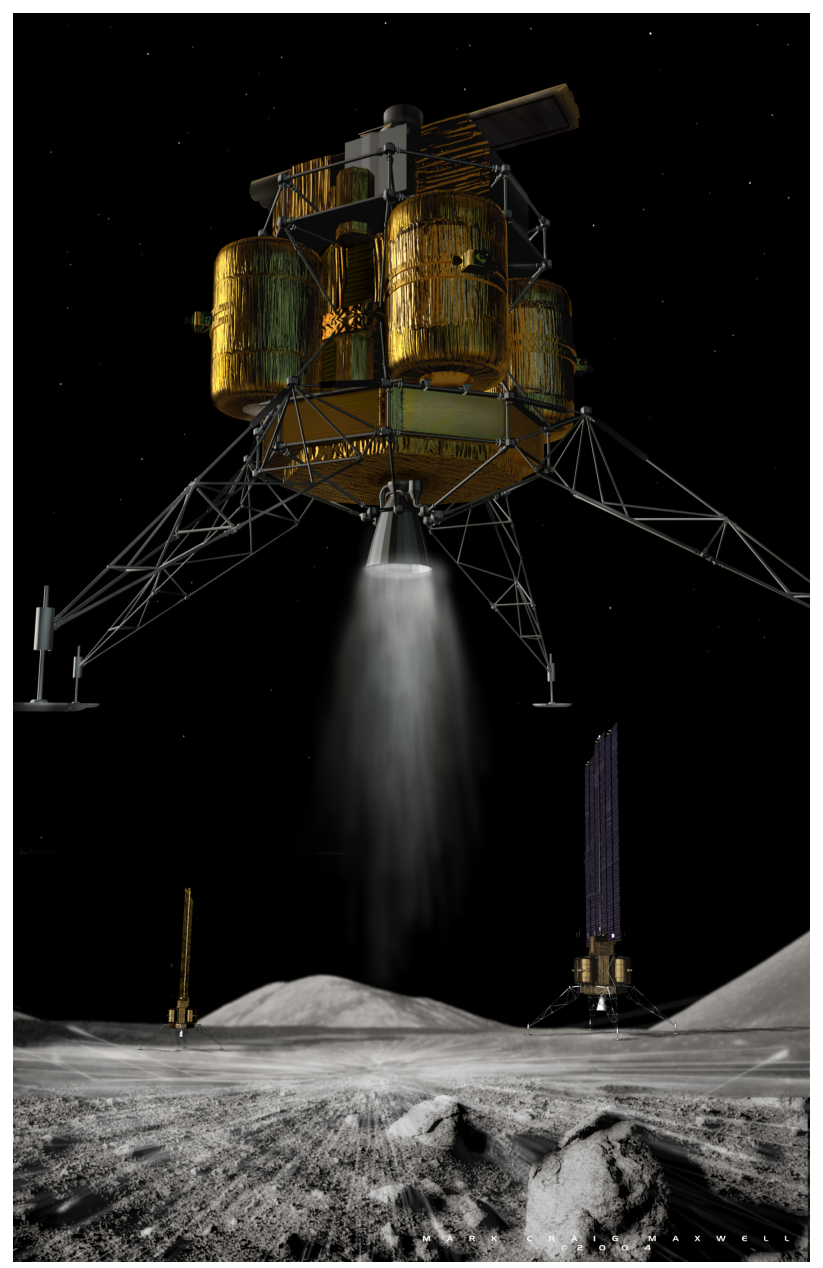

Figure 1 - 100 KW Power Lander (courtesy SkyCorp) 


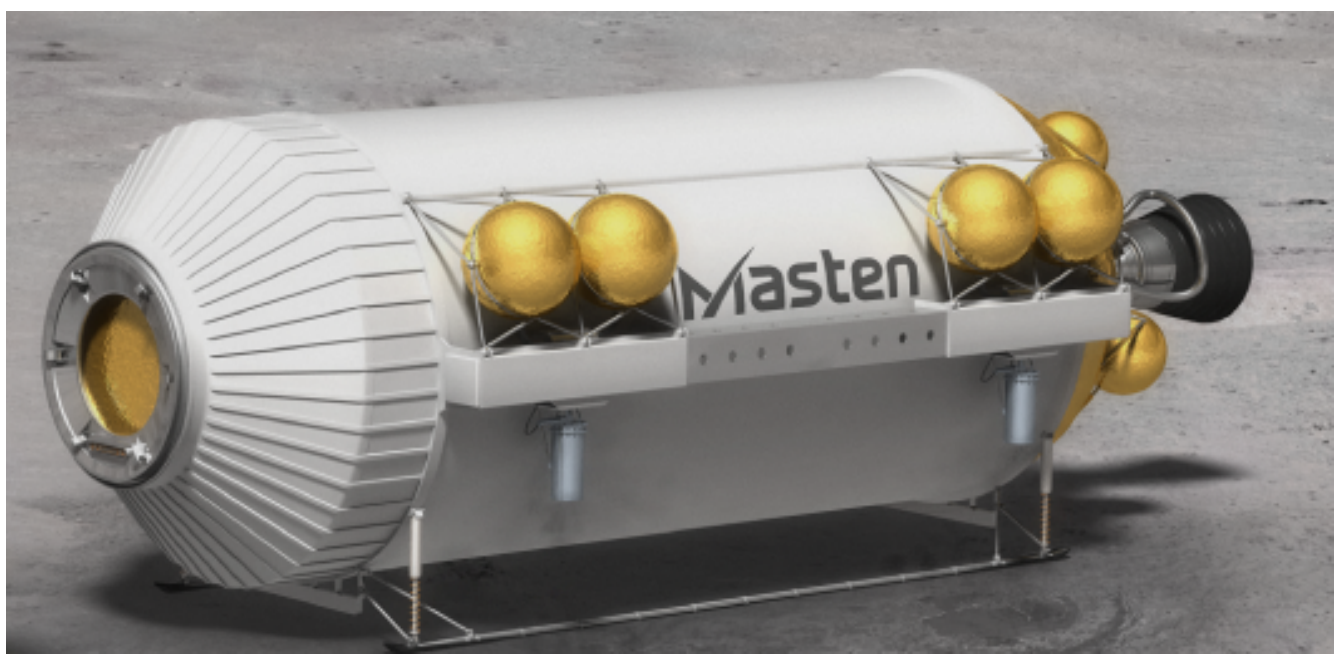

Figure 2 - Illustration of a lunar crew habitat, with attached lunar descent mules (courtesy of Masten Space Systems)

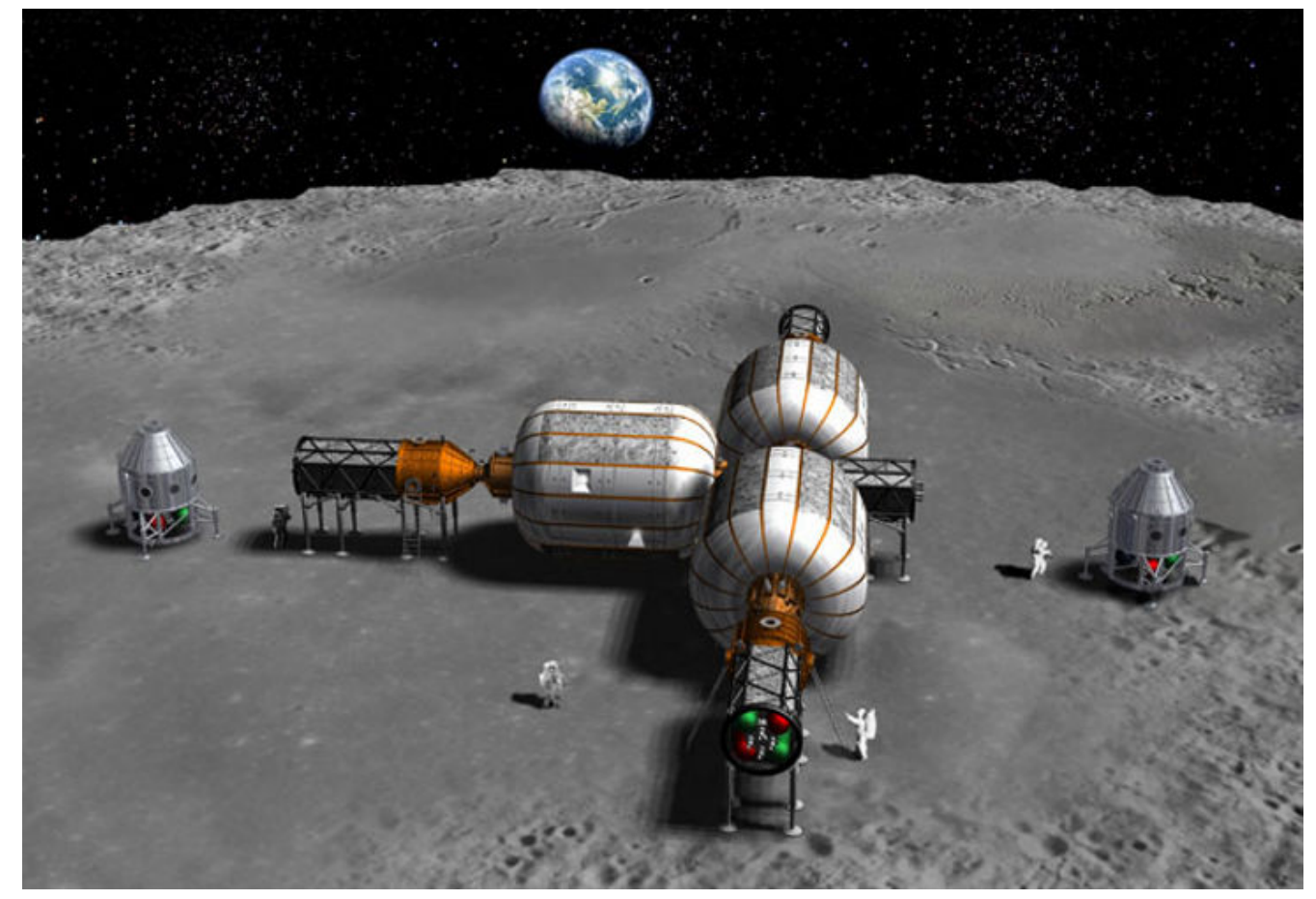

Figure 3 - Illustration of a three-habitat module Lunar Station facility (courtesy of Bigelow Aerospace) 